\title{
Análisis comparado sobre el concepto de tutela judicial efectiva entre los países de Colombia y España.
}

\section{Comparative analysis on the concept of effective judicial protection between the countries of Colombia and Spain.}

\author{
Autores: Luis Ernesto Heras Ramos ${ }^{1}$ \\ Correspondencia: luisheras3450@hotmail.com
}

\begin{abstract}
RESUMEN
En el presente artículo de reflexión se analizará la posibilidad de establecer si en el plano de la justicia efectivamente se presenta la tutela judicial efectiva, por ser un tema relacionado con la administración de justicia y por cuanto la tutela se asocia directamente con los derechos fundamentales de la persona, especialmente la vida, dejando a un lado otro de los derechos fundamentales como es el de la justicia, porque implica quiérase o no de la vida de las personas. Se desarrolló este estudio para determinar la realidad de la tutela judicial efectiva, para ello se realiza un análisis comparado teniendo presente el país de España por tratarse de uno de los más avanzados en el tema. Se basa en los principios estipulados de la tutela judicial la cual se remonta a varios siglos. Metodológicamente se aplicó un tipo de estudio descriptivo - exploratorio, además de con la técnica cualitativa sin abandonar el paradigma de investigación sociojurídica. Se aplica el método deductivo, al ir estudiando comparando para llegar a una conclusión general.
\end{abstract}

\section{Palabras Claves:}

Derecho fundamental, juez, ley, persona.

\begin{abstract}
You can set it at the level of justice do not get to present an effective remedy, because it is an issue related to the administration of justice and because the protection is directly associated with the fundamental rights of the person, especially life, leaving aside other fundamental rights such as justice, because like it or not involves the lives of people. Investigation is being conducted to establish the reality of effective judicial protection, to do a comparative analysis is performed taking into account the country of Spain because it is one of the most advanced in the field. It is based on the stated principles of the judicial protection which goes back several centuries in the past. To develop the kind of descriptive, exploratory court, in addition to qualitative without abandoning the paradigm of socio-legal research technique was applied. Deductive method is applied, as you study comparing to reach a general conclusion.
\end{abstract}

\section{Keywords:}

Guardianship, fundamental right, judge, law, person,

\footnotetext{
${ }^{1}$ Ex Gerente de la Caja de Crédito Agrario seccional Barranquilla, con Amplia experiencia en asuntos del Sistema financiero y Bancario. luisheras3450@hotmail.com
} 


\section{Introducción}

La Carta política colombiana de 1991 puede considerarse a la vanguardia, en términos de modernidad constitucional, trajo consigo muchos avances para la protección de los derechos fundamentales de la persona, por tal motivo se instituyó el derecho de tutela como mecanismo legal para su defensa, también buscó darle acceso a la justicia a la personas, lo cual fue plenamente garantizado por la Constitución, sin embargo hizo falta que el Estado estableciera la protección plena a ese derecho mediante la instauración patente o palmaria de la tutela judicial efectiva.

Sin embargo, al no al no existir una norma expresa sobre la tutela judicial, ni en la Constitución ni en la legislación ordinaria o estatuaria, se crea un problema, al tener que extraerse de conceptos de la Jurisprudencia, la Doctrina, como también de algunos principios tomados de la Carta Magna como; el debido proceso, primacía del derecho sustancial, acceso a la justicia y sobre todo el derecho de acción de tutela, entre otros, lo cual genera dificultes por los tratamientos diferenciales que se le da a estos conceptos en ocasiones en algunas latitudes.

Mientras que para Araujo, R. (2011), el sistema de protección brindado por la constitución se encuentra regido en Colombia por el modelo democrático y social de derecho, que según sus principios tiende a garantizar el control jurisdiccional sobre aquellos conflictos jurídicos debido a relaciones públicas o privadas ( $p$. 249).

De todas formas, la tutela judicial efectiva es de suma importancia cuando las personas tratan de acceder a los servicios de la justicia, es a través de este mecanismo que se puede proteger el derecho a la justicia. 
Realizando una revisión sobre los derechos ubicados en la constitución y que además poseen una connotación procesalista, llegamos a los cánones 29 y 229 , que establecen, el derecho iusfundamental del debido proceso el cual es aplicado a toda actuación judicial y administrativa y el derecho de acceso a la administración de justicia, cuyo último responsable viene a ser el juez, quien es el que debe garantizar la vigencia y supremacía constitucional y legal, y, por tanto, los derechos y garantías reconocidas a los ciudadanos y el ejercicio legítimo y legal de los poderes constituidos (Araujo, R., 2011, p 249). Frente a estos inconvenientes es que formulamos la siguiente pregunta: ¿Qué similitudes y diferencias existen entre la tutela judicial efectiva entre los países de Colombia y España?

Para el desarrollo de la anterior pregunta se hace necesario recurrir a la historia como a ciertas teorías que brinden un marco jurídico donde encaje esta investigación. Para ello se parte de definiciones ya conocidas como: 


\section{Metodología.}

Es un artículo derivado de una investigación enmarcada en el campo jurídico comparativo que empleó el tipo de estudio descriptivo, porque se describieron los hechos objeto de estudio como es la tutela judicial efectiva en Colombia y su parangón con España, además es de corte exploratorio por tratar de acercarse al tema, sin querer ser exhaustivo, también el investigador se apoya en el análisis, para descomponer cada de las partes que forman una tutela, para luego volver ensamblarlas y poder llegar a unas conclusiones concretas.

Por otro lado, es descriptivo al tener presente cada una de las características de la tutela judicial efectiva, al realizar la comparación entre la tutela judicial efectiva que se aplica en el país de España y la que se lleva en Colombia.

También se basará en la técnica del método cualitativo, al no tener que procesar información numérica, los insumos son solo textos, donde no se puede aplicar el método cuantitativo, pero siempre bajo el paradigma de la investigación sociojurídica, por tratarse de un conjunto de supuestos epistemológicos como de herramientas metodológicas que se deben emplear para enunciar el Derecho, partiendo de una concepción fáctica del mismo (Giraldo, J., 2011).

Se acude al método deductivo una vez que las teorías y casos de tutelas se presentan de manera general, como lo que se quiere es aplicarlo en Colombia, sus deducciones serían las enseñanzas a aplicar, es decir se parte de lo general, de las Constituciones de Colombia y España para poder llegar a conocer casos particulares donde se aplique o no la tutela judicial efectiva. El enfoque que se le pretende dar a la investigación es desde la perspectiva filosófica. 


\section{Resultados y discusiones.}

\section{Marco histórico}

La tutela judicial efectiva se remonta posiblemente al siglo XIII, donde en la Carta Magna de 1215, tal como lo sostiene Gozaini, O. (2002), en donde ninguna persona por condición o estamento, se podrá privar de su tierra, como de su libertad, ni será desheredado, como tampoco sometido a pena de muerte, sin que haya respondido a todos los cargos en un debido proceso legal (p. 55).

Por otro lado, se considera que la tutela judicial efectiva tiene sus orígenes en la Revolución Francesa del año 1789, hecho absolutamente incidente en la forma diferente de concebir al Estado, que hasta ese entonces no existía como tal sino a través de la figura de quien detentaba de manera omnímoda el poder, "el rey", el cual gobernaba a su antojo, pero una vez conformado el estado, todo cambió dando lugar a las constituciones con las que se dio paso al establecimiento de la tutela judicial efectiva (Ramírez, B., 2013, p. 24).

Tal como lo expone González, V. (2012), la tutela judicial aparece como un derecho constitucional posterior a la segunda guerra mundial. Por esa época se presentaba mucha arbitrariedad hacia las personas principalmente en los estados fascistas, donde se fueron creando toda una serie de actos del ejecutivo sin mediar un control judicial y de procesos que tan sólo eran para guardar las apariencias (p. 24).

Por su parte, sostiene Araujo (2011), en Colombia se presentó una confrontación histórica definida por la igualdad jurídico-formal en contraposición de la desigualdad socioeconómica, que va más allá del plano procesal, la pregunta que suele hacerse dentro del señalado marco jurídico se refiere a la relación del 
derecho de acceso a la justicia estipulado en el artículo 229 de la Constitución Política con uno de los derechos fundamentales, como es el de la tutela judicial efectiva el cual viene definido por el derecho comparado, especialmente el derecho constitucional alemán, italiano y español, de donde se pueda inferir si el la garantía de acceso a la justicia y el debido proceso forman parte fundamental del derecho a la tutela judicial efectiva o si en un sentido diferente, se está tratando del mismo derecho $y$, en ese orden de cosas sería un concepto de una comprensión e indivisible, capaz de imponer un mandato a todos los organismos del Estado, con el objeto de procurar la igualdad material, intentando un equilibrio entre el ejercicio de las potestades del Estado y los derechos de los ciudadanos (p. 250).

\section{Tutela Judicial Efectiva}

Los autores Chang, M. y Alfonso, R. (2002), consideran que el derecho a la tutela judicial efectiva es aquél por el cual toda persona, como miembro de una sociedad, puede tener acceso a los órganos judiciales para el ejercicio o defensa de sus derechos o intereses, sujeto a que esta persona sea atendida por medio de un proceso que le considere las mínimas garantías para su efectiva realización ( $p$. 18).

Para Gonzales, J. (1985), el derecho a la tutela judicial consiste en el derecho a que toda persona tiene para que se le haga justicia; a que cuando quiera obtener algo de otra, este requerimiento le sea atendido por un órgano judicial, por medio de un proceso donde se contemplen las garantías mínimas (p. 27).

Se hace necesario establecer la relación entre la tutela judicial efectiva y el derecho de las personas a la justicia. Bajo esta premisa, se hace posible mencionar que los Derechos Humanos promulgados por la organización de las 
naciones unidas, en el sentido que se viene indicando hicieron un gran desarrollo al estatuir lo siguiente:

Toda persona tiene derecho, en condiciones de plena igualdad, a ser oída públicamente y con justicia por un tribunal independiente e imparcial, para la determinación de sus derechos y obligaciones o para el examen de cualquier acusación contra ella en materia penal (Recuperado de http://www.un.org/es/documents/udhr/).

Como se busca realizar un análisis comparado entre Colombia y España, es relevante partir de una definición clara sobre la tutela judicial efectiva. Tal como lo expresa Ramones, M. (2009) en su tesis, quien argumenta que la Constitución Española presenta un significativo avance al respecto, donde en dicha constitución se sanciona como derecho fundamental el derecho de acceso a la justicia, ampliando su injerencia, no solo de los ciudadanos frente a las intromisiones del poder público, sino también de cualquier persona ante aquellas situaciones que involucren la tutela de derechos como de intereses legítimos (p. 9).

Una vez teniendo presente la tutela judicial efectiva en el país europeo, el derecho europeo ha querido, seguido por los organismos internacionales de la Comunidad Europea, el poder de ampliar la esfera de garantías de los derechos e intereses fundamentales de las personas, debido principalmente y según Barnés, J. (1993), a la “... trágica experiencia jurídica de la época inmediatamente anterior..." Posteriormente a la Segunda Guerra Mundial y a la dictadura del nacional-socialismo, en la medida en que existían actuaciones del Estado que se encontraban inmunes frente al control jurisdiccional o apariencia de procesos, donde las garantías provistas no eran consideradas ni reales ni efectivas (Araujo, R., 2011, p 258). 
Se puede pensar que en esencia en la Ley de Bonn de 1949 de Alemania, se establece un control jurisdiccional racional y efectivo sobre todo tipo de actuaciones administrativas, que de alguna manera quebrantaban las garantías individuales, partiendo del principio de garantizar al ciudadano, el control pleno y efectivo sobre todas las actuaciones administrativas que puedan colocar en riesgo las garantías individuales, de donde se estime que el poder legislativo deba establecer todo tipo de acciones y recursos jurídicos, así como de proporcionar los medios personales, organizacionales y logísticos que ayuden para promocionar la defensa judicial, y en esa medida no cuente con la posibilidad de excluir materias que hagan parte de la función administrativa del control judicial, ni el juez puede dejar de conocer ninguna (Araujo, R., 2011, p 259).

Además, teniendo como referente al pueblo alemán, la tutela judicial efectiva se fundamenta en la cláusula del Estado de derecho, no podría tratarse de otra manera, por ser este tipo de estado el cual vigila y protege los derechos fundamentales $\mathrm{y}$, desde esta posición, este derecho fundamental resulta ser claro

\section{La tutela judicial efectiva en Colombia}

En Colombia se presenta la tutela judicial efectiva a partir de la Constitución del 91, aunque no exista un articulado expreso para este tipo de tutela, se sostiene que existe un vacío en la Ley, sin embargo se asocia este tipo de tutela con el derecho al debido proceso, mientras que en otros países por ejemplo España y Venezuela en sus constituciones mencionan claramente este derecho para todos los ciudadano, estableciéndose de esta manera sin lugar a dudas la tutela judicial efectiva.

La autora Araujo, R. (2011), dentro de sus argumentos expresa algo muy interesante: 
Parte de la doctrina colombiana considera que la Constitución colombiana reconoce a los ciudadanos el derecho a la tutela judicial efectiva y se señala que esta tiene un carácter prestacional que busca que se despliegue la actividad judicial y se responda a través del proceso a las pretensiones que se formulan, las que deben resolverse con base en el sistema de fuentes establecido por la jurisdicción independiente, imparcial y en un término razonable, mediante una decisión de fondo motivada, salvo que concurran causas legítimas de inadmisión (pp. 269-270).

Además con esta identificación, se trata verdaderamente del derecho de acceso a la justicia como de las garantías que se apartan del debido proceso. Es por ello, que se extrae el derecho fundamental a la tutela judicial efectiva del derecho comparado y del Sistema Interamericano de Derechos Humanos a la totalidad de las garantías procesales que deben encontrarse presentes en todo tipo de procesos y que estrictamente deben ser eficaces para salvaguardar los derechos públicos subjetivos e intereses legítimos (Araujo, R., 2011, p 270).

Como se mencionó anteriormente, en Colombia se le presta mucha importancia al debido proceso, es por ello que al revisar más detalladamente la Constitución del 91 se encuentra que se puede observar que el artículo 29 es la disposición que ha establecido que debe existir el debido proceso a toda clase de actuaciones judiciales y administrativas. Es por ello, que nadie podrá ser juzgado con leyes diferentes a las prexistentes al acto que se le acusa (principio de legalidad o tipicidad), ante juez o tribunal competente (Principio de juez natural) y sometidos a la plenitud de las formas características de cada juicio.

Dentro de la misma constitución se establece que la administración de justicia es una función pública del Estado. Sus decisiones gozan de total independencia, pero sus actuaciones serán públicas y permanentes, pero consultando las excepciones 
que se encuentran dentro de la ley y por tanto ellas permanecerán en el derecho sustancial.

Para develar la existencia de la justicia para todos los colombianos, en su artículo 229 se garantiza el derecho que debe tener toda persona para poder acceder y alcanzar un pronunciamiento de la administración de justicia. Es por ello que la ley indicará en cuales de los casos podrá hacerlo sin que intermedie la representación de abogado.

A su vez los autores Rúa y Lopera (2002), plantean que existen diferentes elementos constitutivos para erigirse en derecho fundamental a la tutela judicial efectiva. Para ellos no se trata de acceso a la justicia, por tratarse de un concepto que viene con la concepción del derecho, por tal motivo debe existir diferencia entre acceso al órgano judicial como acceso a la justicia.

Es muy importante tener presente que el Código General del Proceso o Ley 1564 de 2012 establece claramente la tutela judicial efectiva en su artículo segundo cuando se menciona el acceso a la justicia.

En el presente artículo queda consignado que:

"Toda persona o grupo de personas tiene derecho a la tutela jurisdiccional efectiva para el ejercicio de sus derechos y la defensa de sus intereses, con sujeción a un debido proceso de duración razonable. Los términos procesales se observarán con diligencia y su incumplimiento injustificado será sancionado".

Además de las definiciones anteriores de tutela judicial efectiva, es importante hacer precisiones sobre el análisis comparado por ser el eje fundamental de la investigación, tratando de establecer una comparación entre España y Colombia 
con lo relacionado con la tutela judicial efectiva y de esta forma poder llegar a conclusiones claras y precisas.

\section{Análisis Comparado}

Cuando se menciona el análisis comparado en el derecho, quiere significar entre otras cosas, un método de estudio o de investigación comparativo de las ciencias jurídicas, entre otras una comparación jurídico-dogmática(Aguirre, 2010). El método de la comparación se realiza por medio de la lectura de normas que a través de la formulación del lenguaje, se podrían explicar conforme a la doctrina como de sistemas jurídicos que le sean aplicables al interior de un área de validez (Tamayo, R., 2007, p. 1).

Existen varias ramas del análisis comparado en el derecho, tal como lo explica Morineau, M. (2006). Según esta autora existen tres ramas a saber:

- El análisis comparado descriptivo. Se presenta cuando se analizan las variantes que se pueden hallar entre los sistemas jurídicos de dos o más países.

- El análisis comparado aplicado. Este análisis se refiere a reformas jurídicas entre países, al igual que a la unificación de derechos diferentes.

- El análisis comparado abstracto o especulativo. Este análisis sirve para poder ensanchar la suma total de los conocimientos jurídicos (p. 20). 
Además existe una clasificación para cada análisis comparado, que según De Cruz, P. (1999), consiste en:

- Análisis comparativo entre un sistema jurídico extranjero y el nacional para poder establecer sus analogías y diferencias.

- Poder realizar un análisis objetivo y sistemático de las soluciones encontradas por distintos sistemas jurídicos con relación a un determinado problema jurídico.

- Para poder realizar investigación de la relación causal entre distintos sistemas jurídicos

- Poder realizar comparaciones de las diferentes etapas evolutivas de esos sistemas jurídicos

- Poder realizar un examen de las etapas del desarrollo jurídico general a partir de los momentos y sistemas jurídicos (p. 7). 


\section{Conclusiones.}

A los postre se puede señalar que la tutela judicial efectiva si existe en Colombia, aunque no se encuentra explícitamente señalada en la constitución, pero si en otras normativas como en el código general del proceso. En la práctica jurídica colombiana en realidad es de infrecuente invocación. Desde el punto de vista normativo, se cuentan con las bases para una aplicación efectiva, tal como viene aconteciendo en España, recordemos que es un derecho fundamental el cual debe ser respetado por todos.

Desde otro punto vista, hace falta mucha madurez al país para poder asimilar este tema, tan solo en casi tres décadas desde su promulgación, se requiere de mayor decantación para que aplique de manera imparcial y sin muchos contratiempos en la justicia colombiana.

Es importante establecer que a pesar de no contemplarse expresamente una tutela judicial efectiva se han presentado casos donde las personas la han impetrado para que sus derechos les sean reconocidos, aunque esto es la excepción a la regla, tal como se mencionó anteriormente, su invocación es infrecuente y falta mayor desarrollo doctrinal, en el que se le aborde de manera profunda y detallada, para empezar a hablar de una consolidación doctrinal del principio.

Por su parte la Corte Constitucional, homologando de cierta forma el derecho a tutela judicial efectiva con el derecho de acceso a la administración de justicia, conceptúa en sentencia C-086 de 2016 "que el acceso a la administración de justicia -derecho fundamental a la tutela judicial efectiva- ha sido catalogado como una necesidad inherente a la condición humana. No en vano representa uno de 
los estandartes en un Estado constitucional que, como el colombiano, además de consagrar un generoso catálogo de derechos pregona su auténtica vigencia". De forma categórica para tratar de dar una definición a tutela judicial efectiva la Corte enseña que ésta "se traduce en la posibilidad, reconocida a todas las personas residentes en Colombia de poder acudir en condiciones de igualdad ante los jueces y tribunales de justicia"

Con relación a España, nos llevan años de estar aplicándola, por encontrarse en situación diferente, allá se encuentra expresa, los jueces no tienen que deducirla como en Colombia, donde todo se torna un poco más complejo y dubitativo y más en asuntos judiciales, mientras en España se le reconoce efectivamente, en Colombia en ocasiones se encuentra en discusiones sobre si es o no es tutela judicial efectiva el denominado debido proceso o más bien es el derecho de acceso a la administración de justicia.

Porque una cosa es el debido proceso y otra muy distinta cuando la persona o los abogados saben que tienen que hacer para que se cumpla con la tutela judicial efectiva, cuales son los mecanismos expeditos para su correcta aplicación y no el tener que hacer tramites tortuosos para llegar a lo mismo. 


\section{Referencias}

Aguirre, V. (2010). El derecho a la tutela judicial efectiva: una aproximación a su aplicación por los tribunales ecuatorianos. Foro 14, 1-40.

Antony, C. Acceso a la justicia y tutela judicial efectiva. Aportes de las ciencias penales y criminológicas dirigidas a la víctima. Capítulo Criminológico, 30 (4), 433-458.

Araujo, R. (2011). Acceso a la justicia y tutela judicial efectiva. Propuesta para fortalecer la justicia administrativa. Visión de derecho comparado. Estudios Socio Jurídicos, 13 (1), 247-291.

Barnés, J. (1993), La tutela judicial efectiva en la Grundgesetz. Madrid: Civitas.

Chang, M. y Alfonso, R. (2002). Acerca de la necesidad de legislar sobre las medidas autosatisfactivas en el proceso civil (Tesis inédita de especialista). Universidad Nacional Mayor de San Marcos, Lima, Perú.

Correa, M., Jaimes, J., Cardozo, S. \& Mantilla, C. (2013). Estrategia para la disminución de violencias en la escuela en la ciudad de Bucaramanga. Revista Justicia, 18(24), 14-24. Recuperado de http://publicaciones.unisimonbolivar.edu.co/rdigital/ojs/index.php/justicia/arti cle/viewFile/136/138

Colombia. (2012). Constitución Política de Colombia. Bogotá: Legis. 
Cárdenas, L. (2013). Prácticas de lectura y escritura en la universidad. ¿Qué y cómo leen y escriben los estudiantes de licenciaturas? Revista Amauta, 21, 139-162

Cruz, E. (2015). la Ciudadanía ECológiCa En aBya-yala/ amériCa latina. Amauta, 87-103.

De Cruz, P. (1999). Comparative Law in a Changing World. New York: Cavendish.

Giraldo, J. (2011). Los supuestos teóricos de la investigación sociojurídica. Recuperado de http://www.redsociojuridica.org/documentos/supuestos_ teoricos_investigacion_sociojuridica.pdf.

Gonzales, J. (1985). El derecho a la tutela jurisdiccional efectiva. 2 ed. España: Civitas.

Gozaíni, O. (2002). El debido proceso constitucional. Reglas para el control de los poderes desde la Magistratura Constitucional. Cuestiones Constitucionales, (7), 53-86.

Ley 1564 de 2012. Por medio de la cual se expide el Código General del Proceso y se dictan otras disposiciones. Publicada en el Diario Oficial 48489, del 12 de julio 12 de 2012. Colombia.

Morineau, M. (2006). Bases históricas de la familia jurídica romano-canónica. Instituto de Investigaciones Jurídicas, (1), 12-45. 
Organización de las Naciones Unidas. (2015). Declaración Universal de los Derechos Humanos. Recuperado de http://www.un.org/es/documents/udhr/.

Ramírez, B. (2013). El Derecho a la tutela judicial efectiva en el derecho procesal paraguayo. Paraguay: Universidad Nacional de Itapúa.

Ramones, M. (2009). Tutela efectiva y judicial en la investigación de la fase preparatoria del proceso penal venezolano (Tesis inédita especialista en ciencias penales y criminológicas). Universidad Católica Andrés Bello, Maracaibo, Venezuela.

Rúa, J. y Lopera, J. (2002). La tutela judicial efectiva. Bogotá: Leyer.

Sentencia C-086 de 2016 Corte Constitucional Colombiana, Magistrado Ponente:Jorge Iván Palacio Palacio.

Tamayo, R. (2007). Teoría jurídica y derecho comparado. Una aproximación y un deslinde. Isonomía, (27), 29-39.

Trejos, L. (2013). Aproximación a las dinámicas del crimen organizado en la ciudad de Barranquilla. El caso del Frente José Pablo Díaz de las Autodefensas Unidas de Colombia (200-2006). Justicia, 118-134.

Universidad Católica de Santiago. (2005). La tutela judicial efectiva como instrumento esencial de la democracia. Ecuador: Universidad Católica de Santiago de Guayaquil. 
Vega, H. (2015). Aspectos dogmáticos y políticos criminales de la estructura general del delito en el sistema penal colombiano. Justicia, 27, 42-72. Recuperado de http://dx.doi.org/10.17081/just.3.27.320

Yáñez, M. (2013). El desplazamiento forzado en la jurisprudencia de la Corte Constitucional colombiana (1991-2003): momento previo a la declaratoria forma del estado de cosas inconstitucional. Revista Justicia, (23), 191-218. Barranquilla: Universidad Simón Bolívar 